\title{
Hemispheric Dominance for Task Dependent Frontal Lobe Function \& Its Relationship to Language Lateralization and Handedness
}

\author{
Barshen Habelhah ( $\square$ bhabelhah@theneuroassociates.com ) \\ Neurological Associates - The Interventional Group https://orcid.org/0000-0003-4886-0651 \\ Kennedy D Mahdavi \\ Neurological Associates - The Interventional Group
}

Margaret A Zielinksi

Neurological Associates - The Interventional Group

Sergio B Becerra

Neurological Associates - The Interventional Group

Alexander Bystritsky

UCLA School of Medicine

Michael Mamoun

CNS Health

Taylor P. Kuhn

Neurological Associates - The Interventional Group

Sheldon E. Jordan

Neurological Associates - The Interventional Group

\section{Research Article}

Keywords: functional localization, handedness, dorsolateral prefrontal cortex, language lateralization

Posted Date: June 8th, 2021

DOI: https://doi.org/10.21203/rs.3.rs-503450/v1

License: (1) (1) This work is licensed under a Creative Commons Attribution 4.0 International License. Read Full License 


\section{Abstract}

The present study investigates a potential method to optimize effective functional localization strategies for both language regions and the dorsolateral prefrontal cortex (dIPFC) while in a scanner. This functional task combines elements of creative problem solving, executive decision making based on an internal rule set, and working memory. Retrospective analysis was performed on a total of 58 unique participants ( $40 \%$ female, $M_{\text {age }}=42.84$ years, $\left.S D_{\text {age }}=16.51\right)$. Of these participants, 47 were classified as right-handed, 7 were classified as left-handed, and 4 were classified as "mixed-handed" or ambidextrous according to the Edinburgh Handedness Inventory. The imaging data was judged by two blinded investigators to assess language and dIPFC dominance while using the motor cortex activitation to confirm that participants engaged in the task. We show that $25 \%$ of right handed individuals seem to have a dominant dIPFC localized to the right hemisphere rather than the assumed left, and more than a quarter of left handers were dominant in their left hemisphere. Given the clinical relevance of dIPFC dominance, this task appears to be an evidence-based technique for determining appropriate dIPFC target for the purposes of neuromodulation (e.g. TMS).

\section{Introduction}

Handedness is considered to be one of the more obvious functional asymmetries within the human brain. The neural representation of handedness can be visually confirmed using neuroimaging. Less obvious functional asymmetries, such as language, creative problem-solving, and executive decision making require further investigation to determine neurological lateralization. Language regions (e.g., Wernicke's and Broca's areas) as well as the dorsolateral prefrontal cortex (dIPFC) constitute key functional targets for various therapeutic interventions (Avissar, 2017). The dIPFC is predominantly associated with frontalexecutive skills, such as working memory, decision-making, creativity, and motor planning, and is functionally and reciprocally related to deeper prefrontal areas involved in mood regulation (Miller, 2001). Hemispheric localization varies to some degree with handedness, however, no heuristic used to correlate handedness with language or dominant dIPFC provides certainty. For instance, among a majority of righthanded individuals, dominant language function is most often localized to the left hemisphere. For many left-handed individuals, language may be lateralized to the left hemisphere as well; however, in contrast to right-handers, many left-handed participants will actually show either right hemisphere or bilateral representation.

Effective localization is highly important for decreasing the functional risks associated with neurosurgery and may be useful for determining placement for effective non-invasive stimulation techniques (e.g., transcranial magnetic stimulation, TMS). Repetitive TMS (rTMS) has been shown to mitigate subgenual cingulate hyperactivity in patients with refractory depression, nearly toward levels of healthy patients (Hadas, 2019). However, most literature on the use of rTMS for patients with depression report rTMS application over the left dIPFC rather than the right, assuming that right-handers have a dominant dIPFC on the left hemisphere (George, et al., 2010; George, 2013; Eche, 2012; Perera, 2016). Importantly, it is not 
uncommon for patients to have a negative reaction to right dIPFC rTMS, yielding agitation or mania, requiring switching to the contralateral dIPFC to provide the desired therapeutic effects.

Early imaging experience suggested that depressed patients appear to have decreased activation of the dIPFC with inverse increased activation of the subgenual prefrontal region. Both neurosurgical navigation and rTMS targeting protocols have occasionally deployed seed analysis to determine stimulation sites or establish the bounds of a surgical field. For instance, one technique for localizing the dIPFC involves an anticorrelation seed analysis of the subgenual cingulate (Biver, 1994; Baxter Jr, 1989; Galynker II, 1998; Mayberg, 2005; Chen, 2013; Liston, 2014; Fox, 2012). These techniques have been used to attempt to improve treatment outcomes. In this vein, the present study attempted to use a method to optimize effective functional localization strategies for both language regions and the dIPFC using an fMRI task that combines elements of creative problem solving, executive decision making based on an internal rule set, and working memory.

\section{Methods}

Retrospective analysis was performed on a total of 58 unique participants ( 23 females, $M_{\text {age }}=42.84$ years, $S D_{\text {age }}=16.51$ ). Of these participants, 47 were classified as right-handed, 7 were classified as lefthanded, and 4 were classified as "mixed-handed" or ambidextrous according to the Edinburgh Handedness Inventory.

MRI acquisition was performed on a 1.5 T Siemens Espree scanner equipped with a 16-channel head coil (Erlangen, Germany). A structural image was acquired for the purposes of co-registration with functional data. The T1 weighted anatomical sequence was magnetization-prepared, rapid- acquisition gradientecho (MPRAGE) ( $T R=1810 \mathrm{~ms} ; T E=3.50 \mathrm{~ms} ; \mathrm{FoV}=180 \times 240 \mathrm{~mm}$; resolution $1 \mathrm{~mm}$ isotropic). Each participant obtained blood-oxygen level dependent (BOLD) imaging at rest and with task-dependent activation. Resting state bold images were 8 minutes and 20 seconds long. This functional sequence was acquired with a $T R$ of $2500 \mathrm{~ms}, T E=30 \mathrm{~ms}, \mathrm{FoV}=192 \times 192 \mathrm{~mm}$, resolution $4 \mathrm{~mm}$ isotropic and 200 spatial volumes. The task based BOLD acquisition was similar except fewer volumes - a total of 140 bringing the scan to 5 minutes and 50 seconds. The active task performed during the BOLD sequence was designed to engage the dorsolateral prefrontal cortex (dIPFC) through patient decision-making and creativity. Participants were trained by a technician prior to entering the scanner. While in the scanner, patients were presented with a series of slides containing 3 words; for each slide, patients were instructed to choose one of the words and perform a hand movement that creatively represented the chosen word (Figure 1, Appendix A). This active task was a block-based paradigm, constituting 25 seconds of rest (looking at a cross on the screen), followed by 25 seconds of the described activity.

This task takes advantage of many dLPFC functions including working memory and internally generated decision making. The movement corresponding to the words the patient chose elicits the hand and thumb region of the motor cortex and encourages working memory, as well as internal rule making. Working memory was also highlighted when patients were required to choose a word that had not 
previously been demonstrated. Because these functions have been linked to the dIPFC, the combination of these actions elicited the desired functional network.

Efforts were made to minimize excess motion and to encourage an alert and relaxed state throughout the exam. Data was analyzed using workstations equipped with the Invivo Dynasuite program and other statistical software programs and compared with independent components analysis seed-based correlation analysis, and a power spectral transformation. Computer scoring and human cross checking was performed to ensure adequate processing of artifacts, proper co-registration and appropriate selection of relevant data for final interpretation.

A board-certified neurologist and board certified neuropsychologist verified language and dIPFC localization. Neurology and radiology peer review was performed on completed data sets for quality assurance and for interpretation consensus. Engagement in the task was judged based on whether or not there was significant BOLD activation in the motor strip, primarily in the hand knob area. The imaging data was judged by these two blinded investigators for dominant language hemisphere and dominant dorsolateral prefrontal cortex (dIPFC). Inter-rater reliability was defined by agreement with the 'official' judgment and evaluated by joint probability of agreement.

\section{Results}

All 58 patients' fMRI scans were evaluated by two investigators who were blinded to the handedness of the individual for dominant language hemisphere and dominant dorsolateral prefrontal cortex (dIPFC). Dorsolateral prefrontal cortex agreement between the two investigators who were blinded to the handedness of the individual was $90.6 \%$ (58 scans out of 64 scans), and language dominance agreement between the investigators was $93.8 \%$ (60 scans out of 64 ). Agreement on the correct activation pattern for which hand was utilized for the task was 100\% (47 right handed patients, 7 left handed patients, and 4 ambidextrous patients). Of the 47 right handed patients, 35 (74\%) were left hemisphere dominant for dorsolateral prefrontal cortex and 12 patients $(26 \%)$ were right hemisphere dominant for dorsolateral prefrontal cortex. Of the 7 left handed patients, $5(71 \%)$ were right hemisphere dominant for dIPFC, and 2 (29\%) were left hemisphere dominant. Of the ambidextrous patients, 3 (75\%) were right hemisphere dominant, and 1 (25\%) was left hemisphere dominant. Of the 54 right and left handed individuals, 40 (74\%) showed opposite hemisphere dominance for dIPFC and 14 (26\%) participants showed same hemisphere dominance for dIPFC. 7 (13\%) participants, of the 54 right and left handed participants, showed same hemisphere dominance for language and 47 (87\%) participants showed opposite dominance for language. Of the 4 participants who were ambidextrous, 3 (75\%) showed opposite hemisphere dominance for dIPFC and 1 (25\%) participants showed same hemisphere dominance for dIPFC. Moreover, 2 (50\%) participants, of the 4 ambidextrious participants, showed same hemisphere dominance for language and 2 (50\%) participants showed opposite dominance for language.

All 58 patients received repetitive transcranial magnetic stimulation, with 54\% (31 patients) reporting a clinically significant change in their Beck Depression Inventory scores (30\% decrease in scores). Among 
these 58 patients, one of them received treatment at a different TMS center and was stimulated on the hemisphere opposite the dominant dIPFC. This patient was right handed, and appeared to have a dominant dIPFC localized in the right hemisphere. The initial TMS center they were treated at stimulated the assumed left hemisphere; consequently, the patient reported feeling worse both verbally and on several intake forms (e.g., Beck Depression Inventory, Beck Anxiety Inventory, and Patient Depression Questionnaire). After reviewing the patient's scans and determining where the dominant dIPFC might be located, we stimulated the right dIPFC. The patient subsequently reported a decrease in Beck Depression Inventory and Beck Anxiety Inventory scores by $65.22 \%$ and $30.77 \%$, respectively.

\section{Discussion}

Using the fMRI scans, two blinded investigators assessed language and dIPFC hemispheric dominant. We found a $90.6 \%$ agreement on dominant dorsolateral prefrontal cortex, and a $93.8 \%$ agreement on language localization. In this retrospective analysis, we show that $25 \%$ of right handed individuals seem to have a dominant dIPFC localized to the right hemisphere rather than the assumed left, and more than a quarter of left handers were dominant in their left hemisphere. Of the 54 right and left handed individuals, $74 \%$ showed opposite hemisphere dominance for dIPFC and $26 \%$ participants showed same hemisphere dominance for dIPFC. $13 \%$ of participants showed same hemisphere dominance for language and $87 \%$ participants showed opposite dominance for language. Of the 4 participants who were ambidextrous, 75\% showed opposite hemisphere dominance for dIPFC and 25\% participants showed same hemisphere dominance for dIPFC. $50 \%$ participants, of the 4 ambidextrious participants, showed same hemisphere dominance for language and $50 \%$ participants showed opposite dominance for language. The task completed in the scanner seems to be an efficient way to localize a potential dIPFC target for purposes of TMS.

The patient who received treatment opposite their dominant dIPFC hemisphere reported feeling worse both verbally and on several intake forms (e.g., Beck Depression Inventory, Beck Anxiety Inventory, and Patient Depression Questionnaire). After reviewing the patient's scans and determining where the dominant dIPFC might be located, we stimulated the right dIPFC. The patient subsequently reported a decrease in Beck Depression Inventory and Beck Anxiety Inventory scores by $65.22 \%$ and $30.77 \%$, respectively.

Limitations of this current study include the small number of participants, and the small number of left handed participants compared to right handed participants. Using self-reported intake measures such as the Beck Depression Inventory is another limitation, as they are subject to biases in honesty and introspective ability, and interpretation of questions.

Based on the current study, it appears possible that effective localization of the dominant dIPFC is important for improving the efficacy of therapeutic stimulation techniques, such as rTMS, and for decreasing functional risks associated with neurosurgery. While the number of participants is small, over half of the 58 patients who received rTMS treatments reported a clinically significant change in the Beck 
Depression Inventory scores. Tasks similar to the method used with functional imaging may be one way for effective TMS targeting, as it allows for the patient to activate a region that encapsulates creative problem solving, executive decision making, and working memory.

Another interesting question that could be subject for future research is where the dominant dIPFC would be localized for individuals who were forced to become right handers. This could potentially be why some right handed individuals had a dominant dIPFC localized in their right hemisphere rather than their left. Further research regarding effective targeting is required to determine the most efficient way to localize brain regions responsible for creativity, problem solving, and decision making based on an internal rule set.

\section{Declarations}

\section{Ethical Approval}

All procedures were in accordance with the Declaration of Helsinki, reviewed and approved by the Institutional Review Board prior to enrollment and all participants provided written informed consent.

\section{Consent to Participate}

Patients have consented to participating in this fMRI imaging study

\section{Consent to Publish}

Patients have given consent for publication

\section{Authors Contributions}




\begin{tabular}{llll} 
Name & Location & Role & Contribution \\
\hline $\begin{array}{l}\text { Barshen } \\
\text { Habelhah, } \\
\text { M.A. }\end{array}$ & $\begin{array}{l}\text { Neurological Associates - } \\
\text { The Interventional Group }\end{array}$ & $\begin{array}{l}\text { Corresponding } \\
\text { author }\end{array}$ & $\begin{array}{l}\text { Data collection and analysis, site } \\
\text { management, drafting of the } \\
\text { manuscript }\end{array}$ \\
$\begin{array}{l}\text { Kennedy } \\
\begin{array}{l}\text { Mahdavi, } \\
\text { B.S. }\end{array}\end{array}$ & $\begin{array}{l}\text { Neurological Associates - } \\
\text { The Interventional Group }\end{array}$ & Author & $\begin{array}{l}\text { Data collection and analysis, revision } \\
\text { of the manuscript }\end{array}$ \\
\hline
\end{tabular}

$\begin{array}{llll}\text { Margaret } & \text { Neurological Associates - } & \text { Author } & \text { Data collection and analysis } \\ \text { Zielinski, } & \text { The Interventional Group } & \\ \text { B.S. } & & \end{array}$

\begin{tabular}{|c|c|c|c|}
\hline $\begin{array}{l}\text { Sergio } \\
\text { Becerra, } \\
\text { B.S. }\end{array}$ & Synaptec Network & Author & $\begin{array}{l}\text { Data analysis, revision of the } \\
\text { manuscript }\end{array}$ \\
\hline
\end{tabular}

$\begin{array}{lll}\begin{array}{l}\text { Alexander } \\ \text { Bystritsky, }\end{array} & \text { Lniversity of California, Author } & \text { Revision of the manuscript } \\ \text { M.D. } & & \end{array}$

Michael CNS Health Author $\quad$ Contribution of participants
Mamoun,
M.D.

\begin{tabular}{llll}
\hline $\begin{array}{l}\text { Taylor } \\
\text { Kuhn, Ph.D. }\end{array}$ & $\begin{array}{l}\text { University of California, } \\
\text { Los Angeles }\end{array}$ & Author & $\begin{array}{l}\text { Data analysis, statistical analysis, } \\
\text { revision of the manuscript }\end{array}$ \\
\hline $\begin{array}{l}\text { Sheldon } \\
\text { Jordan, } \\
\text { M.D. }\end{array}$ & $\begin{array}{l}\text { University of California, } \\
\text { Los Angeles }\end{array}$ & $\begin{array}{l}\text { Principle } \\
\text { investigator, } \\
\text { Author }\end{array}$ & $\begin{array}{l}\text { Study design and conceptualization; } \\
\text { revision of manuscript }\end{array}$ \\
\end{tabular}

\section{Funding}

This study did not receive study support

\section{Competing Interests}

The authors report no conflicts of interest

\section{Availability of Data and Materials}

Data will be made available to qualified users upon formal request

\section{References}

1. Blake, D. T., Byl, N. N., \& Merzenich, M. M. (2002). Representation of the hand in the cerebral cortex. Behavioural Brain Research, 135(1-2), 179-184.doi:10.1016/s0166-4328(02)00163-8

2. Svoboda, K., \& Li, N. (2018). Neural mechanisms of movement planning: motor cortex and beyond. Current Opinion in Neurobiology, 49, 33-41. doi:10.1016/j.conb.2017.10.023 
3. Duboc, V., Dufourcq, P., Blader, P., \& Roussigné, M. (2015). Asymmetry of the Brain: Development and Implications. Annual Review of Genetics, 49(1), 647-672. doi:10.1146/annurev-genet-112414055322

4. Avissar, M., Powell, F., llieva, I., Respino, M., Gunning, F. M., Liston, C., \& Dubin, M. J. (2017). Functional connectivity of the left DLPFC to striatum predicts treatment response of depression to TMS. Brain Stimulation, 10(5), 919-925.

5. Miller EK, Cohen JD. An integrative theory of prefrontal cortex function. Annu Rev Neurosci 2001;24:167-202

6. Biver F, Goldman S, Delvenne V, LuxenA, De Maertelaer V, Hubain P, et al. Frontal and parietal metabolic disturbances in unipolar depression. Biol Psychiatry 1994;36(6):381-8

7. Baxter Jr LR, Schwartz JM, Phelps ME, Mazziotta JC, Guze BH, Selin CE, et al. Reduction of prefrontal cortex glucose metabolism common to three types of depression. Arch Gen Psychiatry 1989;46(3):243-50

8. Galynker II, Cai J, Ongseng F, Finestone H, Dutta E, Serseni D. Hypofrontality and negative symptoms in major depressive disorder. J Nucl Med 1998;39(4):608-12

9. Barrett, J., Della-Maggiore, V., Chouinard, P. A., \& Paus, T. (2004).Mechanisms of Action Underlying the Effect of Repetitive Transcranial Magnetic Stimulation on Mood: Behavioral and Brain Imaging Studies. Neuropsychopharmacology, 29(6), 1172-1189. doi:10.1038/sj.npp.1300411

10. Marangell LB, Martinez M, Jurdi RA, Zboyan H. Neurostimulation therapies in depression: a review of new modalities. Acta Psychiatr Scand 2007;116(3):174-81.

11. Loo CK, Mitchell PB. A review of the efficacy of transcranial magnetic stimulation (TMS) treatment for depression, and current and future strategies to optimize efficacy. J Affect Disord 2005;88(3):255-67.

12. Mayberg, H. S., Lozano, A. M., Voon, V., McNeely, H. E., Seminowicz, D., Hamani, C., ... Kennedy, S. H. (2005).Deep Brain Stimulation for Treatment-Resistant Depression. Neuron, 45(5), 651660.doi:10.1016/j.neuron.2005.02.014

13. Hadas, I., Sun, Y., Lioumis, P., Zomorrodi, R., Jones, B., Voineskos, D., ... Daskalakis, Z. J. (2019). Association of Repetitive Transcranial Magnetic Stimulation Treatment With Subgenual Cingulate Hyperactivity in Patients With Major Depressive Disorder. JAMA Network Open, 2(6), e195578. doi:10.1001/jamanetworkopen.2019.5578

14. Chen, A. C., Oathes, D. J., Chang, C., Bradley, T., Zhou, Z.-W., Williams, L. M., ... Etkin, A. (2013).Causal interactions between fronto-parietal central executive and default-mode networks in humans. Proceedings of the National Academy of Sciences, 110(49), 1994419949.doi:10.1073/pnas.1311772110

15. Liston, C., Chen, A. C., Zebley, B. D., Drysdale, A. T., Gordon, R., Leuchter, B., ... Dubin, M. J. (2014).Default Mode Network Mechanisms of Transcranial Magnetic Stimulation in Depression. Biological Psychiatry, 76(7), 517-526.doi:10.1016/j.biopsych.2014.01.023 
16. Fox, M. D., Buckner, R. L., White, M. P., Greicius, M. D., \& Pascual-Leone, A. (2012). Efficacy of Transcranial Magnetic Stimulation Targets for Depression Is Related to Intrinsic Functional Connectivity with the Subgenual Cingulate. Biological Psychiatry, 72(7), 595603.doi:10.1016/j.biopsych.2012.04.028

\section{Figures}

\section{Frog}

\section{Wave}

Crab 
Figure 1

Active Task "On" Slide. Active Task "Off" Slide. 